of references shows. To the best of our knowledge, no UK dentist has ever been successfully sued for utilising night guard dental bleaching when informed consent has been obtained. Dental bleaching itself has never been illegal as the Chief Dental Officer for England has stated. Rather the UK government wants to regulate dental bleaching products under their particular interpretation of a European Directive.

While for the government this rather embarrassing regulatory farce continues, dentists are wise to remember that irreversible and destructive alternatives such as veneers, crowns or post crowns are not nearly as safe as dental bleaching. The irony is that the ledgers of the defence organisations are peppered with dentists being sued for the adverse outcomes of these destructive procedures used to manage discoloured teeth, especially when informed consent has failed to cover the safer option of dental bleaching. ${ }^{1}$

V. Patel, M. Kelleher, M. McGurk

London

1. Kelleher M G D. The 'Daughter Test' in aesthetic ('esthetic') or cosmetic dentistry. Dent Update 2010: 37: 5-11.

DOI: 10.1038/sj.bdj.2010.459

\section{NO RESPONSE}

Sir, I welcome your editorial devoted to the problem of the future treatment of the edentulous and its reference to my recent paper in your Journal. ${ }^{1}$ That paper not only showed the reduction in teaching and experience available to current undergraduates, but also reported the view held by respondents to the questionnaire that official checks and balances, which should be provided by officialdom, such as GDC visitations, were failing to ensure that GDC guidelines are being met.

Subsequent to publication of the paper, I sent electronic copies to a number of organisations that should be concerned by the reported findings, such as the Minister of Health, the Conservative shadow health spokesman, and two different GDC email addresses with a request that copies be sent to all members of GDC. Initially no response was received from any of them. Then a chance contact with my local parliamentary candidate prompted an acknowledgement from the Conservative shadow for dentistry, but offered no further consideration until after the general election. Subsequently, I sent a hard copy by recorded delivery to the Chairperson of GDC. I have not had an acknowledgement from her either.

This does not bode well for the future treatment of this unfortunate group of patients.

\section{R. Clark}

1. Clark R K F, Radford D R, Juszczyk A S. Current trends in complete denture teaching in British dental schools. Br Dent J 2010; 208: E10.

DOI: 10.1038/sj.bdj.2010.460

\section{NONSENSICAL SUGGESTION}

Sir, I refer to your editorial Beware the irony of the humble full-full (BDJ 2010; 208: 327) and in this context wish to point out the foolishness of the GDC policy of refusing the reduced fee registration for retired practitioners. In 45 years of making dentures I have probably done more than any of today's recruits would find to do in several centuries. This wealth of practical experience is just thrown away because of the excessive cost of full registration and insurance required merely to teach voluntarily or for a modest honorarium. In making full prostheses there is no substitute for practical experience and passing that on should be a priority. Instead it is ridiculed and cast aside. The nonsensical and unsafe modern suggestion that impressions for full dentures should be taken with the patient supine demonstrates the point very well.

A. Carmichael

By email

DOI: 10.1038/sj.bdj.2010.461 